\title{
The analysis of conceptual reading violations in pupils with special learning disabilities in terms of cognitive-activity approach
}

\author{
Ludmila Lopatina ${ }^{1}$, Ludmila Baryaeva $^{2}$, and Mariya Ivleva ${ }^{3 *}$ \\ ${ }^{1}$ The Herzen State Pedagogical University of Russia, Speech Therapy Department, 191186 \\ Moika Emb. 48, St. Petersburg, Russian Federation \\ 2 Moscow City University, Speech Therapy Department, 129226 2-oi Sel'skohozjajstvennyj \\ proezd 4, k. 1, Moscow, Russian Federation \\ ${ }^{3}$ The Herzen State Pedagogical University of Russia, Speech Therapy Department, 191186 \\ Moika Emb. 48, St. Petersburg, Russian Federation
}

\begin{abstract}
The article is devoted to the analysis of violations of various types of conceptual reading (scanning, reading for gist, reading for detail comprehension) in pupils with the delay of mental development (DMD). The analysis is based on the cognitive-activity approach, which allows us to consider the mechanism of understanding the text message not only as a language process, but also as a speech-thinking process, which has its own goals, means and technology. The article describes the results of the research that characterizes the manifestations and cognitive mechanisms of conceptual reading violations in pupils with specified type of dysontogenesis. There are analyzed the variable nature of the difficulties of using different strategies for processing text information in children with the delay of mental development in accordance with the communicative and cognitive task. There is characterized the connection between the violations of different types of conceptual reading in pupils with DMD and the features of the processes of goal formation, cognitive instruction.
\end{abstract}

\section{Introduction}

Currently, the general informatization of society, socio-cultural changes determine the necessity of interpretive reading skills, which provide not only an understanding of the text sense, but also a critical evaluation of the read text; easy and competent usage of the information which is obtained in the process of reading; finding the necessary facts etc. The development of effective reading activity is of particular importance for students with special educational needs, along with overcoming specific reading disorders (dyslexia), due to deviations in the process of reading mastering, insufficient formation of psychophysiological prerequisites for reading, lack of cognitive operations that provide processing of the text.

\footnotetext{
${ }^{*}$ Corresponding author: m.g.ivleva@yandex.ru
} 
In modern theoretical sources [1-4] conceptual reading is considered as a conscious choice of the type of reading in accordance with a given cognitive instruction and the usage of appropriate strategies, tactics of text information processing. If there is an instruction for selective extraction of information, the strategy of scanning reading is actualized. This strategy aims to selecting of factual information which is presented in the names, dates, numeral elements with the obtaining a superficial understanding of the content of the read from the text. The presence of the cognitive task of understanding the most important, essential information from the text requires actualization the strategy of reading for gist, in which secondary facts can be omitted or remain unclear. Instruction for the comprehensive, accurate understanding of the basic and secondary information involves the usage of the strategy of reading for detailed comprehension, which is associated with a detailed interpretation of all the facts read, with their further memorization and productive usage. A number of interiorized interactive processes and cognitive skills provides the possibility of actualization of a particular strategy during conceptual reading: selection, inferention, conceptual integration, conceptual composition [5], which play an important role in the processing of text information. Selection provides extraction, systematization of semantic and language units of the text; conceptual integration is responsible for synthesizing the general sense on the basis of comparison and completion operations; conceptual composition allows to combine the selected concepts into a new concept; inference is associated with the extraction of implicit information. The result of these cognitive mechanisms action is the processing of text information, its transformation.

Thus, in the implementation of different types of conceptual reading, the reader solves the cognitive task. It consists in certain transformations of the read text, which are aimed at understanding different types of information and understanding the general sense of the text.

Currently, there are quite a number of research, which reveal the features of understanding the text information by students with special educational needs. Gorbunova S. Y. analyzed the retellings the read text and revealed that the majority of children with systemic speech disorders is characterized by fragmentation, difficulties of reproduction of certain facts; by different kind of addition [6]. Bryzgalova S. O., Bunyan L. G. conducted the experimental research of the semantic component of reading [7]. This research demonstrated that students with the delay of mental development are characterized by difficulties in establishing causeand-effect relationships in the text, mistakes in the definition of the main events, the main characters.

Analyzing the features of text comprehension while reading in children with learning disabilities, Abandiano Helen R., Turner Jesse [8] revealed the difficulties of logical understanding of descriptive texts in comparison with the understanding of narrative texts. The authors point out that the possible reasons for this may be such factors as: less familiar structure of the descriptive text, not familiar vocabulary, unformed skills of word recognition (division into syllables, recognition of words parts), lack of knowledge.

Despite the active Russian and foreign research of the semantic component of reading, we can claim that there are not taken into account the cognitive mechanisms and operations which are involved in the process of conceptual reading and which perform certain functions. At the same time, the cognitive-activity approach is progressive in the research and correction of the violations of conceptual reading. It allows us to consider the process of understanding the text information as a complex interpretative activity that has a certain technology, goals and means. The importance of this approach using is noted by foreign researchers, which have found that the presentation of the cognitive instruction to use a certain strategy before reading, during reading and after it contributes to a more productive understanding of the read text in pupils with learning disabilities [9]. As noted by Van den brook, Espin Christina A. [10], the existing tools for assessing reading comprehension do not take into account the operations, which are involved in the reading process. The combinations of them depend on 
the features of the text, the goals of the text, the reader's instruction. In the process of experimental training Ailers Linda H., Pinkley Christina [11] determined the productivity of the cognitive approach in the development of reading comprehension in first-graders. The authors based on the consideration of reading as a metacognitive process, which is provided by a number of interiorized interactive processes and cognitive skills.

\section{Description of sample}

The research data were obtained on the basis of a probabilistic cluster sample of two groups of schoolchildren. The first group (experimental) consisted of 30 seventh grade pupils with the delay of mental development (DMD). The second group (a group for comparative analysis) included 30 pupils of the seventh grade with normal speech and intellectual development. The presence of such a diagnosis (DMD) in schoolchildren was confirmed by the conclusions of psychological-medical-pedagogical commission, which were made for admission to the school. According to the documentation from speech therapist, the majority of test subjects with DMD had violations of oral speech (17 pupils had the conclusion of the speech therapist - "systemic underdevelopment of speech"); disorders of writing and reading (22 pupils - "mixed dysgraphia", "mixed dyslexia").

The population of children with this type of dysontogenesis is widely represented among schoolchildren with special learning disabilities. As we know, pupils with DMD have a slow rate of formation of various characteristics of cognitive, personal, emotional spheres, lack of regulatory mechanisms of activity [12]. These factors can negatively affect the quality of processing, understanding, usage of text information. In this regard, the considered category of schoolchildren was chosen as an experimental group.

\section{Methods of research}

The usage of cognitive-activity approach made it possible to determine the leading directions and content of the study. It includes the assessment of the prerequisites for the development of conceptual reading and the procedural and resultative components of different types of reading in schoolchildren with the delay of mental development (DMD). In this article, we are going to consider the features of the skills and abilities of processing text information by schoolchildren with DMD in the process of scanning, reading for gist and reading for detailed comprehension. Let us briefly describe the technology of the research. The research of scanning reading assumed a cursory reading of the text within a set time and extraction of the required factual data (names, numeral elements, etc.). In order to research the strategy of reading for gist, pupils were asked to answer questions on reading, reproducing mainly conceptual information of the text; as well as to select key words that are "carriers" of the general sense of the text. The research of reading for detailed comprehension assumed preparation of a detailed retelling and expressive reading of the literary text. The stimulus material was non-fiction and literary texts, which are included in the list of literature for extracurricular reading.

The obtained results were analyzed qualitatively and quantitatively on the basis of scorelevel assessment. Mathematical and statistical data processing was also carried out (the significance of differences between the experimental group and the group for comparative analysis was revealed using the U-Mann-Whitney criterion).

\section{Main results of the research}


The research of the scanning reading demonstrated the difficulties of carrying out search activity in the text of students with the DMD, the lack of functioning of the mechanism of semantic forecasting, the difficulties of distinguishing between essential and secondary information, the defects of ordering the selected elements. The most part of the schoolchildren (13 people out of 30) did not demonstrate the required tactics of operating with the text in accordance with a given communicative instruction, and therefore did not have time to complete the set time scanning the text and select the necessary factual information. They were characterized by the confusion, replacement of specific data, which were caused not only by the incompleteness of viewing the text, but also by the imperfection of orientation in the organization of the text space. Such types of mistakes were typical for some pupils of the group for comparative analysis ( 3 people out of 30 ). Ignoring the given instruction for a cursory reading of the text by pupils and the implementation of a more familiar sequential reading of the text led to the mechanical memorization of factual units without their analysis, to the lack of purposeful selection of the necessary facts. The majority of schoolchildren with DMD (15 people out of 30) and the third part of children from control group (10 people out of 30) perceived this cognitive instruction for the selection of information. But they did not have time to conduct its logical and semantic processing, and therefore at the same time, pupils did not have time to make its logical and semantic processing, which led to the presence of confusion, distortion of factual data. Features of implementation of scanning reading by schoolchildren with DMD indicates an insufficient functioning of different cognitive operations. They are forecasting of the contents on the heading, separate sentences, on the beginning and the end of the text; selection of specific information, its correlation with a given instruction; establishment of semantic links between separate facts; elimination of secondary information in the process of viewing the text. Only 2 pupils of the experimental group (out of 30) showed a sufficient level of formation of search activity on the text. In the group for comparative analysis, 17 people (out of 30) showed such a high result.

The analysis of the features of reading for gist in schoolchildren with the DMD allowed to identify that the majority of pupils with DMD (17 people out of 30) have low level of formation of reading for gist. They are characterized by significant difficulties in understanding the main content of the read, manifested in the form of incorrect transmission of the chain of semantic relations of the story, in the distortion of its content, in the wrong allocation of key, text-forming words. Only 3 people out of 30 from the comparison group showed similar results.

The smaller part of the schoolchildren of the experimental group (13 out of 30) showed insufficient understanding of the main content of the reading. This group of pupils made some mistakes in establishing and transmitting the chain of the most complex types of connections in the text (causal, target), semantic inaccuracies, they needed the help of the experimenter in the form of leading questions for the selection of reference words. However, in general, they were guided in the semantic, syntactic relations included in the story. Some such mistakes were observed in 12 schoolchildren with normal development (out of 30), but most of them (15 people out of 30) correctly and accurately reproduced the conceptual information of the text, answering questions, competently selected keywords.

Insufficient formation of reading for gist in schoolchildren with the delay of mental development is caused by the inability of the active transformation of lexical items in the semantic violation of the triggers (key words), which provide the formation of semantic complexes in the transition from explicit language code to the implicit intellect code. The results of the research of reading for gist in pupils with the DMD showed insufficient formation of different cognitive mechanisms. They are the selection of the main content and the definition of the main idea; the distinction between the main and secondary information; semantic compression; selection of key words; orientation in the compositional and semantic 
structure of the text and compositional integration; establishing a chain of links between events, heroes; formulation of conclusions, which are based on the information of the text.

The violations of integrity and coherence in the structuring of the secondary text were revealed during the research of the reading for detailed comprehension in schoolchildren with the DMD. The paraphrases were made by pupils with the DMD as a result of the reading for detailed comprehension. They show that in some cases (15 people out of 30) there are difficulties of definition of the main structural fragments of the text content, of establishment of their sequence and clarification of implicit semantic relations between them. In others cases (12 people out of 30) there is a distortion of the real image of the content because of the inclusion of "extra-context" episodes, that is due to associativity of thinking, insufficient operation of mental operations of combining and integrating elements of the content already available in the experience. Along with this, a general concept of the text was formed.

The difficulties of retelling in schoolchildren with the DMD are caused by the insufficient functioning of the mechanisms of semantic compression, operations of probabilistic forecasting; difficulties of keeping in working memory the conceptual information associated with the transmission of the text content; slow search of semantic dominants. These mechanisms are necessary for semantic processing of information and content space of the text. Only 3 schoolchildren with the DMD (out of 30) had no difficulties in reproducing the text which was read. In comparison, the majority of pupils of the group for comparative analysis (24 people out of 30 ) did not experience difficulties in retelling, only in a few cases (6 people out of 30) there was a lack of expansion of the text, mainly due to the omission of irrelevant details.

The results of the research of the reading for detailed comprehension also showed the difficulties of selection and competent usage of intonation and expressive means of speech by schoolchildren with the DMD to convey the semantic structure of the written text when reading aloud. The majority of pupils (16 people out of 30 ) was characterized by mistakes in changing the temporal contour of the sentence; deviations of the pausal division of the sentence; difficulties in placing the logical stress. A smaller part of the experimental group (11 people out of 30 ) used expressive means when reading aloud partially and only 3 people - correctly used them. In comparison with them in the group for comparative analysis only 5 people experienced some difficulties expressive reading, most of them ( 25 people out of 30 ) correctly and accurately coped with the task.

The specific character of the expressive means usage by pupils with the DMD indicates about the following: 1) these means are underdeveloped; 2) the confines of understanding are narrow; 3 ) there is the negative impact on the semantics of sentences; 4) there is a difficulty of detecting and understanding the implied sense.

The features of the reading for detailed comprehension in pupils with the DMD indicate the difficulty of establishing a logical sequence of facts in text; the difficulties of the facts grouping; difficulties of determining the effects of one conceptual part to another; insufficiency of the inference mechanism (detection and understanding of the implied sense, implicit meaning).

The results obtained during the tasks were processed in the program STATISTICA 6.0 using the U-Mann-Whitney criterion. It was found that for each task there are statistically significant differences $(p \leq 0.01)$ between the results of schoolchildren with the delay of mental development and schoolchildren of the group for comparative analysis.

\section{Discussion of the results}

Thus, the obtained experimental data indicate that schoolchildren with the delay of mental development are generally able to understand the facts, phenomena and events, which are reflected in the text, but they are characterized by significant difficulties in establishing and 
interpreting causal relationships in the text, most often not explicitly expressed. For most pupils with the DMD the understanding of textual information does not operate as autonomous cognitive task that is needed to be solved for understanding the read text. Insufficient inclusion of cognitive operations in the conceptual processing of the text causes its deficiency in the interpretation of the text message.

\section{Conclusions}

1. The analysis of the research results, taking into account the cognitive-activity approach, revealed the difficulties of conceptual reading in schoolchildren with the delay of mental development. These difficulties are expressed in the inability to analyze the purpose of reading, to choose the appropriate type of reading (scanning, reading for gist and reading for detailed comprehension), to use the necessary cognitive techniques, strategies for working with the text, to plan reading activity.

2. The qualitatively heterogeneous nature of the difficulties of mastering different types of conceptual reading is characteristic of children with DMD. This is due to the lack of functioning of the transformational processing operations of the text, providing understanding of text information.

3. Underdevelopment of conceptual reading abilities in schoolchildren with the delay of mental development is also due to the peculiarity of the processes of goal formation. The child is presented with variable communicative and cognitive goals of the reader's activity in the process of scanning, reading for gist and reading for detailed comprehension. These goals help to focus attention on certain aspects of understanding text information. The difficulties of implementation of these goals in accordance with the cognitive task, as well as their transformation in the process of a reader's activity, negatively affect the productivity of the comprehension of textual information.

\section{References}

1. L.A. Mosunova, Vestnik VGGU. 2-1, 151-157 (2011)

2. G.V. Prantsova, E.S. Pomanicheva, Modern reading strategies: theory and practice. Conceptual reading and working with text (Forum, Moscow, 2016)

3. N.N. Smetannikova, Teaching reading strategies in grades 5 to 9: how to implement the FGOS (Balass, Moscow, 2011)

4. D. S. McNamara, Reading Comprehension Strategies: Theories, Interventions, and Technologies (Lawrence Erlbaum Associates, New York, 2007)

5. L.V. Babina, Cognitive foundations of secondary phenomena in language and speech (Tambov, 2003)

6. S.U. Gorbunova, Correctional and pedagogical education. 4, 27-38 (2016)

7. S.O. Brizgalova, L.G. Beniya, Philological education in the period of childhood, 25, 173 $178(2018)$

8. H.R. Abadiano, J. Turner, New Eng. Reading Ass. J. 38(2), (2002)

9. A. G. Boardman, S.B. Vaughn, P. Reutebuch, Colleen Roberts, G. Klingner, Exceptional Children, 82(4), (2016)

10. P. Van den Broek, C. A. Espin, School Psychology Review, 41(3), (2012)

11. Linda H. Eilers, Christine Pinkley, Reading Improvement, 43(1), (2006)

12. L.B. Baryaeva, I.G. Vechkanova, U.S. Gallyamova Children with the delay of mental development: experimental study and directions of correctional work (Moscow, 2018) 